\title{
Withholding and withdrawing of life sustaining treatment in the newborn
}

\section{J Tripp, D McGregor}

Arch Dis Child Fetal Neonatal Ed 2006;91:F67-F71. doi: 10.1136/adc.2004.068569

The rapid progress of medical technology has resulted in more opportunities to maintain the life of infants in serious and potentially life threatening situations. Whether to treat such infants is a common dilemma. The burden of these difficult decisions rests almost equally on distraught parents and relatives and on the professional staff of neonatal units. Sometimes, either parents or care teams choose to seek a decision from the courts. Ways of reaching the best possible and most inclusive consensus decisions are examined in this review.

See end of article for authors' affiliations

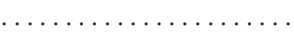

Correspondence to: J Tripp, Child Health, Peninsula Medical School, Church Lane Heavitree, Exeter EX2 5SQ, UK; ¡htripp@ex.ac.uk

Accepted 18 July 2005
1 $\mathrm{n}$ the practice of neonatal care the rapid progress of medical technology has resulted in an increased number of opportunities to maintain the life of infants in serious and potentially life threatening situations where the prognosis for future wellbeing is uncertain or poor. This is particularly problematic in infants of very low gestation who, even when healthy, may be near the limit of potential for normal development ex utero. To treat or not to treat is not an uncommon dilemma, and withdrawal of active medical care is a relatively common event before death. ${ }^{1-4}$

The burden of these hugely difficult decisions will rest almost equally on distraught parents and relatives and on the professional staff of neonatal units. Families may have the benefit of advisory and support systems in the community including religious advisers. Professionals may increasingly seek advice from colleagues or others whose ethical opinion they value, or from hospital or national ethics advisory committees. ${ }^{15}$ Exceptionally, but perhaps increasingly, either parents or care teams may choose to seek a decision from the courts.

Currently the issue of withholding or withdrawal of medical treatment and extraordinary care has been the subject of numerous publications including a recently revised framework for practice from the ethics committee of the $\mathrm{RCPCH}^{6}$ and guidelines from the $\mathrm{GMC}^{7}$ and the BMA. ${ }^{8}$ The principles of practice enunciated in the framework and guidelines are very similar. They are derived from extensive ethical and legal debate and are accepted by the main branches of the major world faiths. ${ }^{6}$ In spite of this apparent consensus, such decisions have recently been the subject of judicial proceedings when parents and professionals have disagreed. ${ }^{9}{ }^{10}$ In contrast with the picture that many infer from media coverage of court cases, the vast majority of such decisions are taken with the confident agreement of all concerned professionals and the parents, usually after careful consideration of the medical, ethical, and social issues. Although these cases currently rarely reach court arbitration, the shift towards a more legislative culture could make this more common. Courts, although making rulings, often neither change minds nor satisfy the parties to the proceedings. This article will suggest that professionals may be able to reduce the number of occasions when agreement with parents cannot be reached, without resort to the courts.

In a survey of doctors on neonatal intensive care units in seven European countries, 1235 (86\%) respondents reported high rates of personal involvement in either withholding or withdrawing treatment ranging from $45 \%$ to $90 \% .{ }^{11}$ Two qualitative studies of parental involvement clearly show the reality of this. ${ }^{12}{ }^{13}$ McHaffie et $a l^{13}$ found that a small minority of nurses and doctors $(3 \%$ and $6 \%$ ) felt that "the ultimate decision should be taken by parents" whereas the majority (58\% and $73 \%$ ) favoured joint decision making. In contrast, $56 \%$ of parents perceived the decision to be theirs, and $42 \%$ that they had accepted lone responsibility; only $14 \%$ perceived it as a joint decision. Brinchmann et al ${ }^{12}$ found that, although a few parents thought that the decision had already been made, the majority, although involved, respected the expertise of the doctor and felt that the burden of responsibility should be shared. This confirms the professional's view identified by McHaffie et al. ${ }^{13}$

\section{THE BACKGROUND}

Changes in legislation, judicial judgments, and development in medical practice combined with evolving public perception of medical practice contributed to the College's decision to update their widely welcomed framework. ${ }^{6}$ Doyal and Larcher ${ }^{14}$ described the difficulty of constructing guidelines in this controversial and ethically contentious area of practice where an appropriate balance is difficult to achieve. It is nevertheless an area where doctors, nurses, and other members of the professional team (hereafter referred to as professionals, recognising that all the staff and advisers to a unit may be involved) must be well informed. Professionals should not only be fully aware of the ethical and legal issues but also about how to manage such difficult decisions to the satisfaction of parents, the judiciary, and the public. Entitling the document "A framework" rather than "guidelines" emphasises that ethical decision making must be informed by personal values. The text does not 
provide cut and dried answers, but clearly identifies areas that need resolution. The other half of the decision making team-the parents-are unlikely to have already had the opportunity for such self reflective consideration of the problem, before this critical and incredibly stressful time. A key professional responsibility is to support and inform, yet not overpower the parent's autonomy as the infant's "best friend".

The nub of the problem is summarised in the first paragraph of the executive summary:

"The RCPCH acknowledges that all members of the health team, in partnership with parents, have a duty to act in the best interests of the child. This includes sustaining life and restoring health to an acceptable standard. However, there are circumstances in which treatments that merely sustain 'life' neither restore health nor confer other benefit and hence are no longer in the child's best interests." ${ }^{\prime 6}$

Biomedical ethics are highly complex, but nonetheless are pervasive in the everyday practice of medicine. The framework addresses the ethical and legal complexities and considers the process of decision making in considerably more detail than can be attempted in this article. Here we explore some issues where we believe a better understanding of how different perspectives might impact on decision making and suggest processes that may reduce the need for judicial decision making. These hinge on medical professionals investigating and being aware of the basis of their own views and developing skills to find a genuine consensus that can be applied in practice.

As in the framework, the article will not address the separate question of withdrawal of care. It assumes that, whatever decisions are made about medical interventions, no neonate will be exposed to withdrawal of care, comfort, or palliation. ${ }^{18}$ Neither will the issue of euthanasia, which is illegal in Britain, be discussed, nor the ethics of abortion for congenital malformation leading to disability. These issues are currently the subjects of active and relevant ethical and legal debate. ${ }^{14}{ }^{15}$ In the recent cases already mentioned, where the question of ongoing medical care of infants required a judicial decision, the principles of the framework and guidelines referenced above were accepted by the courts and referred to in their judgments. Although it is noted that the judgments were made "on the facts of the case" so that no new law has been established, it appears reasonable to conclude that the main principles of the framework are accepted in law. ${ }^{10} 16$

\section{SITUATIONS WHERE DISAGREEMENT IS LIKELY}

Disagreement between parents and professionals about the proper course to take may arise in many circumstances, of which we will explore some. Parents and professionals may disagree when either the parents or the professionals are in favour of continuation (or of withholding/withdrawal) and the other opposed.

Disagreement may result from personal interpretation of, or group adherence to, less prevalent religious beliefs. The latter include those of Jehovah's witnesses, who have major concerns about the use of blood, or some sects of the Jewish faith, who have major anxieties about the process of withdrawal (an act of commission) as opposed to withholding treatment (an act of omission). ${ }^{17}$

Most individuals are able to accept the premise that we should not act to cause an outcome that is unacceptable to the individual to whom the treatment is to be applied (a consequentialist argument). Others will see an overriding obligation not to participate in any action that either directly or indirectly causes death of another human being (either a duty based or deontological argument). We suggest that professionals might more often take a consequentialist ethical view based on their clinical experience of the potentially profound future problems for people with very severe impairments. These two bases of ethical decision making often result in different conclusions as to the ethical solutions. When parents and professionals are basing behaviours on different systems, disagreements are likely. ${ }^{18}$

Further areas of disagreement may arise from different interpretations of the principle of autonomy. Neonates are not autonomous so that the responsibility for decision making passes to others, in particular parents. This creates potential for difference of opinion with professionals, who may feel that they have a better appreciation of the best interests of the infant. ${ }^{13}{ }^{19}$ Firstly, disagreement may arise simply from a difference in evaluation of the medium or long term future for the neonate. Secondly, even having reached an agreed understanding of the infant's potential for physical survival and prognosis, there may be disagreement about whether a life of this expected quality is considered worth while and of value. Finally, it may be that the interests of the parents-for example, the fulfilment of a profound desire for a child of their own-may be perceived by professionals to be contrary to the best interests of the infant.

\section{UNDERSTANDING DISAGREEMENT}

There may be exceptional circumstances where one or other party holds completely rigid views with an unshakeable confidence in the rightness of their beliefs. It is hoped that all professionals and most parents will accept that in issues of this magnitude and complexity there is always some degree of uncertainty. In fig 1 this uncertainty is represented in a schematic graphical form where the decision to treat or not to treat is plotted against the expected severity of outcome or expectation of inevitable early mortality (or both). The part of the hypothetical graph where such a decision is at least debatable is shown by divergence of the two lines. No central or mean line has been drawn within the two lines that are notionally equivalent to a confidence interval for the decision that might be made.

No presumption can be made as to whether parents or professionals may find their position situated either above or below the other's position as regards a yes/no decision in a single scenario. At the left extreme, a point is reached where the two lines coincide; there is no real potential for disagreement here. This will extend to the point where well infants require no medical intervention for intact survival. The lines at the right extreme never quite meet; there is nearly always the opportunity to at least briefly attempt an extension of life, and there are people who feel that such opportunities should always be taken. Clearly, the most difficult decisions, and those with the greatest chance of being unable to reach a consensus decision, are in the area where the lines are furthest apart. Ultimately this is a

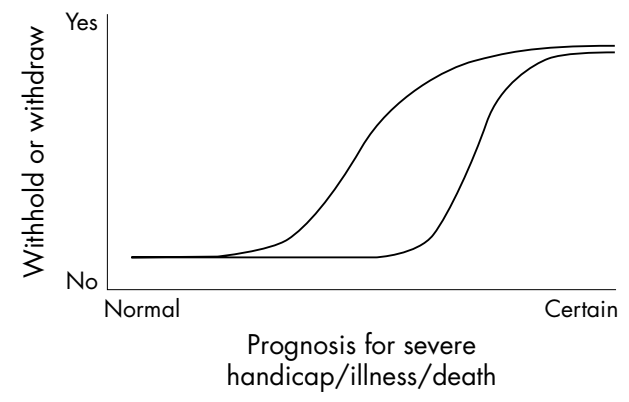

Figure 1 Parents and professionals may have similar views at either end of the graph but in the area of most uncertainty they may have different views. 
dichotomised decision: to treat or not to treat. The graph is representing where the greatest collective uncertainty exists. This is where fewer individuals or groups will immediately agree the necessary dichotomised solution.

\section{MINIMISING THE CHANCES OF UNRESOLVED DISAGREEMENTS \\ Recognition/acceptance of indeterminacy}

Professionals first need to recognise when they are facing a decision in this indeterminate area. It is less likely that parents will be in a position to do so, at least initially, or that the whole clinical team will arrive at a decision at the same time. An open deliberation of this uncertainty by the professional team with the parents will avoid highly divisive perceptions. Such perceptions may include feelings that a decision has "already been made" and the team are simply looking for parental endorsement or that it is a "them and us" situation. A single answer must be reached (to continue or withdraw). There may be no black or white answer that feels "right" to everyone. Helping everyone involved to recognise this from the start allows time for reflection and coming to terms with solutions to which individuals may originally have been strongly opposed.

In interviews with bereaved parents, in a local confidential enquiry that has been running for over 10 years, parents often feel that the possibility of withdrawal of active medical care comes as a complete surprise or "bolt out of the blue" after their prognostic enquiries have been met with relatively optimistic outlooks. This suggests benefits from openness about uncertainties from the earliest possible time. As parental enquiries are often directed to more junior personnel, early team discussion and planning of how to communicate a deteriorating clinical picture to parents is vitalespecially while there is still considerable uncertainty. We believe that many parents simply do not "hear" the, possibly slightly coded, negative statements. To address this locally, we are piloting giving parents a CD recording of important conversations with clinicians about prognosis and/or early discussions about the possible need for difficult decisions (MW Quinn, personal communication).

\section{Parental views should carry strong weight}

As the BMA handbook states: "Their [the parents] views are usually [should be] determinative unless they conflict seriously with the interpretation of the child's best interests by those who are providing care." ${ }^{20}$ In strictly legal terms, when there is an irresolvable disagreement, parents-while having the legal right to consent to treatment for their children-do not have an absolute right either to refuse treatment judged to be in the best interests of the child or to demand treatment to sustain the life of their child. ${ }^{10}$ Professionals should note the use of the word "seriously" and carefully consider whether it will be in the long term interest of the child and family to oppose their view to the extent of court resolution. The ruling by the Honourable $\mathrm{Mr}$ Justice Munby in the Burke v GMC clearly emphasises the importance of patient and family member views. ${ }^{21}$ Subsequent discussion in the BMJ rapid responses highlights the current relevance of this topic. ${ }^{22} 23$

Clearly there will be occasions when clinicians will feel very strongly about the best interests of the child, and two recent decisions by the court confirm the validity of these. ${ }^{9}{ }^{10}$ Professionals should bear in mind that the UN Convention on the Rights of the Child clearly spells out the responsibilities of society to support parents in the application of their beliefs and in their ultimate position of prime responsibility for the welfare of their children. ${ }^{24}$ We suggest that, if professionals are uncertain to any degree, then there is sufficient uncertainty for them to accept the determinative responsibility of parents. Only when convinced that the parent's view is one that a reasonable person could not support should they consider referral for court arbitration to determine what the neonate's "best interests" are. Such arbitration has a role in ensuring that the medical community checks that its moral views remain in line with those of society.

The other side of the equation is that individual professionals should have the right to determine how and when their skills are used. If they feel that use of those skills is going to cause unacceptable suffering, they must be allowed to withdraw their service. However, they have a responsibility to encourage the parents to seek help from another professional or group. Regularly seeking a fully informed and independent second opinion within or from outside the treatment unit may help either party to recognise the validity of the other's view. Such advice may perhaps come, for example, from a colleague with similar religious beliefs to the parents such as a "priest" or elder from their religion, as recommended in the framework.

\section{Working with parents in decision making; sharing or taking responsibility}

Although both parents and professionals have rights, it is usually going to fall to the professional team, who have to take the actions resulting from the decision, to elicit how much of their "rights" parents want to exercise-bearing in mind the responsibility and potential for guilt that comes with a right of determination. Exploratory work with parents is required to discover how they wish the final decision to be made and how much responsibility they wish to take. The professional description of the decision can vary from "these are the facts and we are asking for your decision" to "we have now come to a conclusion as to what is the best course of action and are looking for your consent to carry it through".

Parents may not want to feel that this responsibility is actually ever allocated, preferring that a consensus appears to be an equally shared responsibility. Some may not wish to be put in a position where they have to say yes or no at all, even within a group decision. To follow through with decided actions means that clinicians are putting themselves at risk of later recrimination, a risk that not all professionals are willing to take. We suggest that this sort of risk taking is highly professional. The professional's willingness to take responsibility for the decision is likely to be an important mechanism to allay parental guilt. Some parents may actually welcome the opportunity to be completely relieved of the decision and turn to the courts. However, this may be rare, and the judiciary recognise the difficulties the court faces in making such decisions.

Table 1 shows one helpful formulation of the doctorpatient relationship. ${ }^{25}$ In the context of neonatal care, the model provides a framework within which a professional can visualise the multiple dimensions that need to be considered and plan what styles of interaction are required for particular cases. The Emanuels propose that "The physician with a caring attitude is the ideal embodied in the deliberative model, the ideal that should inform laws and policies that regulate the physician-patient relationship." The intricate and delicate discussions surrounding implementation, maintaining, withholding, or withdrawing treatment in the realm of the neonate is highly complex. The Emanuels consider it important that patients, in this case parents, can be guided through the decision making process by open discussion with professionals. However, professionals must be prepared to enunciate their own values and worthiness of their approach, thus following a more deliberative/interpretive pathway. We suggest that this cannot be undertaken without 
Table 1 Doctor-patient relationship

\begin{tabular}{|c|c|c|c|c|}
\hline & \multicolumn{4}{|l|}{ Doctor's style } \\
\hline & Informative & Interpretive & Deliberative & Paternalistic \\
\hline Parent values & $\begin{array}{l}\text { Defined, fixed, and known } \\
\text { to the parent }\end{array}$ & $\begin{array}{l}\text { Inchoate and conflicting } \\
\text { requiring elucidation }\end{array}$ & $\begin{array}{l}\text { Open to development and } \\
\text { revision through moral } \\
\text { discussion }\end{array}$ & $\begin{array}{l}\text { Objective and originated by } \\
\text { doctor }\end{array}$ \\
\hline Doctor's obligations & $\begin{array}{l}\text { Providing relevant factual } \\
\text { information and implementing } \\
\text { parent's selected intervention }\end{array}$ & $\begin{array}{l}\text { Elucidating and interpreting } \\
\text { relevant parent values as } \\
\text { well as informing the parent } \\
\text { and implementing the parent's } \\
\text { selected intervention }\end{array}$ & $\begin{array}{l}\text { Articulating and persuading the } \\
\text { parent of the most admirable } \\
\text { values as well as informing the } \\
\text { parent and implementing the } \\
\text { parents selected intervention }\end{array}$ & $\begin{array}{l}\text { Promoting the neonates best } \\
\text { interests independent of the } \\
\text { parents }\end{array}$ \\
\hline $\begin{array}{l}\text { Conception of parent's } \\
\text { autonomy }\end{array}$ & $\begin{array}{l}\text { Choice of, and control over, } \\
\text { medical care }\end{array}$ & $\begin{array}{l}\text { Self understanding relevant } \\
\text { to medical care }\end{array}$ & $\begin{array}{l}\text { Moral self development } \\
\text { relevant to medical care }\end{array}$ & Assenting to objective values \\
\hline Conception of doctor's role & Competent technical expert & Counsellor or advisor & Friend or teacher & Guardian \\
\hline
\end{tabular}

the professional first evaluating, understanding, internalising, and being able to justify their views. Nothing is likely to be achieved without first building a trusting relationship, giving parents the opportunity to share in the issues, beliefs, and experiences that shape our perspectives.

In "withhold or withdraw" situations a plan of action with which neither party is altogether happy may be the best that can be achieved. This is firstly because there is a real dilemma with no "good" or "right" answer, but only a "best", and secondly because parental autonomy must be respectedunless it clearly and unarguably contravenes the infant's rights. Reassurance from colleagues, experts, ethical committees, and, exceptionally, the court can be immensely valuable to the decision making process. For advisors beyond the immediate team to go further and prescribe their own preferred course of action may deny the personal autonomy of both parents and professionals. This is clearly unhelpful in the immediate situation. We believe it would also be undesirable in the context of setting patterns for future decision making by undermining the freedom to hold different ethical views autonomously.

Although ethics is often perceived to be a personal and cultural matter, debate on such issues to try and achieve a societal consensus is important. As previously suggested, different people or groups may be using different ethical frameworks, so that withdrawal of treatment may be regarded as taking an action to cause death whereas withholding a treatment is not. After extensive discussion, the ethics committees of both the RCPCH and the BMA concluded that there is no ethical distinction. Nevertheless it is pragmatic to adopt "if in doubt treat and think later" if there is insufficient time for a considered decision. ${ }^{51326}$ This practice also addresses the common situation in the delivery suite where the staff team making the decision may be relatively junior; the decision has to be immediate and taken in relation to the infant of an anaesthetised or at least severely stressed mother. If we are aware that either some of the professionals or the parents believe that the two situations are ethically distinct and treatment withdrawal is always unethical, then phrasing a proposed intervention as a time limited therapeutic trial may help. Some doctors are trying to find strictly mechanical solutions to avoid human action to withdraw treatment by installing timers on ventilators to help overcome a procedural difficulty to allow an ethically justifiable outcome from their particular perspective. ${ }^{17}$

\section{HOW CAN PROFESSIONALS MAXIMISE THE CHANCES OF A JUST AND ETHICAL CONCLUSION?}

From the above discussion it is clear that professionals acting in this area of clinical practice require a number of specialist skills that have not been traditionally formally taught in either the undergraduate or postgraduate curriculum. In the "traditional" medical education experienced by most consultants, ethical questions were often simplified, sometimes to the extent that they were reduced to an understanding of the Hippocratic Oath. This deficit is recognised and increasingly addressed at both levels of education. ${ }^{2}$ Many undergraduates will now receive some formal teaching in relation to the underlying principles of ethical decision making. Most medical postgraduates in paediatrics will expect to have a practical framework for the way in which they give bad news. In relation to communication skills, both are likely to have received formal training, and recent candidates will have been assessed. We are not aware of widespread uptake of the few training courses that would give professionals confidence that they had an internalised and practical framework for dealing with the situation addressed here. A very useful and practical checklist for putting the process into operation, which we fully endorse, was included in the paper of Shooter and Watson. ${ }^{4}$

\section{CONCLUSION}

Adequate implementation of the new edition of the Framework for practice requires a broad knowledge and reflective application of ethical, medical, sociological, biological, and psychological principles in highly stressful environments and highly charged situations. Senior doctors are often counsellors, facilitators, providers, and gatekeepersroles that are often in opposition to each other. As team leaders they must be open to the perspectives and positions held by others, especially parents, but also members of the whole team of professionals. They should be prepared to negotiate and explore the relevant issues in order to reach the best possible and most inclusive consensus decision.

All professionals must think clearly and be open, honest, and empowered to identify their own uncertainties, whether clinical or ethical. A better understanding of ethical theory and attention to some of the issues described here, while openly working to the widely accepted frameworks of the RCPCH and others to guide decision making, will facilitate fully inclusive discussion. We suggest that this will allow a coming together of differing views, thereby avoiding potential conflict.

\section{ACKNOWLEDGEMENTS}

We gratefully acknowledge the very helpful critical review by a number of key individuals including Dr Victor Larcher, Dr Jim Gilbert, Dr Michael Quinn, Dr Claire Foster, Professor John Saunders, Professor Raymond Tallis, and Dr Alan Watson, and the journal referees Ian Laing and Michael Weindling. The text remains our responsibility. 


\section{Authors' affiliations}

J Tripp, D McGregor, Peninsula Medical School, Universities of Exeter and Plymouth, Drake Circus, Plymouth PL4 8BX, Devon, UK

Competing interests: none declared

Table 1 reproduced with kind permission from JAMA 1992;267:2221-

6. Copyright ${ }^{\circ}$ 1992. American Medical Association. All rights reserved.

\section{REFERENCES}

1 Campbell AGM. Ethical problems in neonatal care. In: Rennie JM, Robertson NRC, eds. Textbook of neonatology. Edinburgh: Churchill Livingstone, 1999:1345-50.

2 Hope T, Savulescu J, Hendrick J. Medical ethics and law: the core curriculum. London: Churchill Livingstone, 2003:157-75.

3 McHaffie HE. Crucial decisions at the beginning of life. Oxon: Radcliffe Medical Press Ltd, 2001:1-4.

4 Shooter M, Watson A. The ethics of withholding and withdrawing dialysis therapy in infants. Pediatr Nephrol 2000;14:347-51.

5 Royal College of Physicians. Ethics in practice: background and recommendations for enhanced support. London: Royal College of Physicians, 2005.

6 Royal College of Paediatrics and Child Health. Witholding or withdrawing life sustaining treatment in children: a framework for practice, 2nd ed. London: Royal College of Paediatrics and Child Health, 2004.

7 General Medical Council. Witholding and withdrawing life-prolonging treatments: good practice in decision making. London: General Medical Council, 2002.

8 British Medical Association. Witholding and withdrawing life-prolonging treatment. Guidance for decision making, 2nd ed. London: British Medical Association, 2001.

9 Editorial. Aiding decision making for baby Charlotte and baby Luke. Lancet 2004;364:1462.

10 England and Wales high court of justice: family division. Portsmouth NHS trust $\checkmark$ Wyatt \& ors. http://www.bailii.org/cgi-bin/markup.cgi?doc $=/$ ew/cases/ $\mathrm{EWHC} / \mathrm{Fam} / 2004 / 2247 . \mathrm{htm} \mid$ \&query = Portsmouth+NHS+trust\&method = all 17 November 2004 (accessed 18 Feb 2005).

11 Cuttini. M, Nadia M, Kaminski $M$, et al. End-of-life decisions in neonatal intensive care: physicians' self reported practices in seven European countries, Lancet 2000;355:2112-18.
12 Brinchmann BS, Førde R, Nortvedt P. What matters to the parents? A qualitative study of parents' experiences with life-and-death decisions concerning their premature infants. Nurs Ethics 2002;9:388-404.

13 McHaffie HE, Laing I, Parker A, et al. Deciding for imperilled newborns: medical authority or parental autonomy? J Med Ethics 2005;27:104-9.

14 Doyal L, Larcher VF. Drafting guidelines for the withholding or withdrawing of life sustaining treatment in critically ill children and neonates. Arch Dis Child Fetal Neonatal Ed 2000;83:F60-3.

15 Rivers RPA. Decision making in the neonatal intensive care environment. $\mathrm{Br}$ Med Bull 1996;52:238-45.

16 Alexander Harris Solicitors. High court decision on Luke Winston-Harris. http://alexanderharris.co.uk/article/ High_Court_decision_on_Lukes_future_treatment_2146.asp (accessed 2 Mar 2005).

17 Ravitsky V. Timers on ventilators. BMJ 2005:330:415-17.

18 Schwartz LS, Preece PE, Hendry RA. Medical ethics: a case based approach. Edinburgh: Saunders, 2002:1-66.

19 Wood NS, Costeloe K, Gibson AT, et al. The EPICure study: growth and associated problems in children born at 25 weeks of gestational age or less. Arch Dis Child Fetal Neonatal Ed 2003;88:F492-500.

20 British Medical Association Ethics Department. Medical ethics today: the BMA's handbook of ethics and law, 2nd ed. London: British Medical Association, 2003:131-64.

21 England and Wales high court of justice (Administrative Court) Decisions. Burke v General Medical Council. http://www.bailii.org/cgi-bin/ markup.cgi?doc $=/$ ew $/$ cases $/$ EWHC/Admin/2004/ 1879.html\&query = burke\&method = all (accessed 5 Jul 2005)

22 Gillon $\mathbf{R}$. Why the GMC is right to appeal over life prolonging treatment. $B M$ 2004;329:810-11.

23 llangarante J, Otto S, James T, et al. Rapid responses to - Why the GMC is right to appeal over life prolonging treatment. http://bmj.bmijournals.com/ cgi/eletters/329/7470/810 (accessed 5 Mar 2005).

24 Office of the high commissioner for human rights. United Nations convention on the rights of the child. http://www.unhchr.ch/html/menu3/b/k2crc.htm (accessed 5 Apr 2005).

25 Emanuel EJ, Emanuel LL. Four models of the physician-patient relationship. JAMA 1992;267:2221-6.

26 Thames regional perinatal group. Guidelines relating to the birth of extremely immature babies (22-26 weeks gestation). http://www.bapm.org/ documents/publications/immature.pdf (accessed 5 Jul 2005). 